\title{
Benign prostatic hyperplasia and lower urinary tract symptom guidelines
}

\author{
Claus Roehrborn, MD, FACS \\ Professor and Chair, Department of Urology, University of Texas Southwestern Medical Center at Dallas, Dallas, Texas
}

Cite as: Can Urol Assoc J 2012;6(5):S130-2. http://dx.doi.org/10.5489/cuaj.12231

\section{Abstract}

Lower urinary tract symptoms (LUTS) are very common in men, with incidence increasing with age. Several clinical practice guidelines are available as decision-making aids for men with LUTS and the recommendations are based on the presumed etiology of the symptoms (due to obstruction, overactive bladder or a combination of the two). This review presents the various pharmacologic treatment options and summarizes key clinical trial data supporting their use.

ower urinary tract symptoms (LUTS) are very common in men, with an increase in prevalence correlating with increasing age in a linear manner. ${ }^{1}$ Approximately $50 \%$ of men over the age of 50 have histological benign prostatic hyperplasia (BPH) and approximately $25 \%$ of men over 50 have moderate-to-severe LUTS. Clearly, not all men with BPH develop LUTS. In addition, not all men with LUTS have BPH as the underlying cause.

For clinicians who treat LUTS in men, there are several relevant clinical practice guidelines that are available to help guide management decisions. This review will focus on the guideline recommendations with respect to pharmacotherapies, and include highlights of the key clinical trial evidence supporting the inclusion of these therapies among the recommended management options.

\section{What are the most recent, relevant guidelines?}

The most recent evidence-based recommendations in this field are the 2012 Guidelines on the Management of Male LUTS, published by the European Association of Urology (EAU). ${ }^{2}$ The American Urological Association (AUA) and the United Kingdom's National Institute for Health and Clinical Excellence (NICE) published guidelines for BPH and male LUTS, respectively, in 2010.3,4 Finally, the recommendations of the International Scientific Committee (ISC) on the Evaluation and Treatment of Lower Urinary Tract Symptoms in Older Men were published in 2009. ${ }^{5}$

\section{Pharmacologic options}

Each of the published guidelines mentioned above recommend the use of several different pharmacotherapies for the treatment of LUTS, depending on the clinical situation. Figure 1 shows the algorithm presented in the ISC recommendations (2009). ${ }^{5}$ The following is a review of the recommended pharmacologic treatment options. Surgical interventions are addressed in another section of this supplement.

\section{Antimuscarinics}

Antimuscarinics can be used to treat men with symptoms consistent with overactive bladder $(\mathrm{OAB})$ and no bladder outlet obstruction (BOO), or those with mixed symptoms suggestive of combined $\mathrm{BOO}$ and $\mathrm{OAB}$ pathology. The data supporting this recommendation are primarily from studies investigating tolterodine. For example, in a post-hoc analysis of men with BOO and confirmed detrusor overactivity included in two studies, there was a significant reduction in frequency of urgency-related micturition. ${ }^{6}$ However, at present there is a lack of prospective data from longer-term studies for the use of antimuscarinics in patients at risk (i.e., larger glands and higher residual urine at baseline).

\section{Alpha-blockers}

The evidence base is much more compelling for the use of alphablockers for men with BOO. For those men with smaller prostates and/or low prostate-specific antigen (PSA), the guidelines recommend monotherapy with an alpha-blocker as the primary pharmacotherapy. There are several such agents approved for this indication; ${ }^{7-11}$ these agents appear to have similar efficacy, but do have some differences in terms of tolerability and safety profiles.

The mechanism of action (MOA) of the alpha-blockers for $\mathrm{BOO}$ is modulation of contraction of the smooth muscle in the prostate, bladder base and neck, and urethra. Yet, these agents do not address the underlying prostate growth. Over time, the prostatic enlargement can progress to an extent where alpha-blockade has limited or no effect on symptoms. 


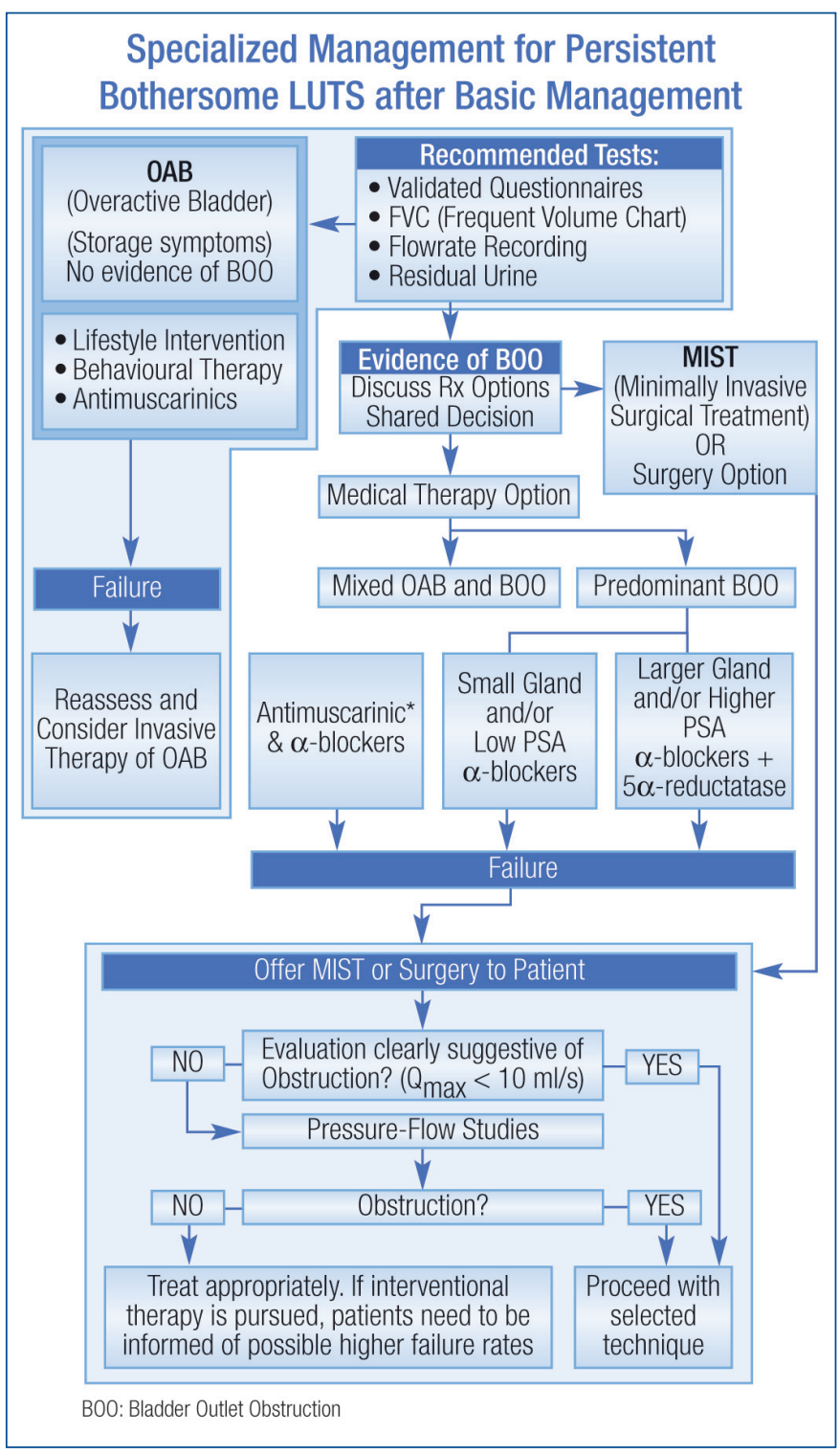

Fig. 1. Algorithm for the treatment of lower urinary tract symptoms in men.

\section{Combination alpha-blockers +5 -ARa}

The pharmacotherapy that does have a direct impact on prostate size is antagonism of 5-alpha-reductase (5-AR). For men with larger prostate volumes and/or high PSA, each of the guidelines recommends combination therapy with an alpha-blocker and a 5-AR antagonist (e.g., dutasteride, finasteride). Antagonism of 5-AR has been shown to reduce retention even when used alone. ${ }^{12}$ However, there are better outcomes when the 5-AR antagonist is combined with an alpha-blocker, as observed in the Medical Therapy of Prostatic Symptoms (MTOPS) and Combination of Avodart and Tamsulosin (CombAT) studies. ${ }^{12,13}$ In both studies, there were also higher incidences of adverse events in the combination arm versus either agent as monotherapy.

\section{Combination antimuscarinics + alpha-blockers}

For patients with mixed $\mathrm{OAB}$ and $\mathrm{BOO}$, the combination of an antimuscarinic and an alpha-blocker has been shown to be more beneficial than alpha-blockade alone. ${ }^{14-17}$ Fixed-dose combinations of these agents are in development.

\section{PDE-5 Inhibition}

PDE-5 inhibitors (e.g., tadalafil) are not currently recommended in any published guideline, but the evidence suggests that they soon will be. The proposed MOA of these agents for the treatment of LUTS is a beneficial effect on smooth-muscle relaxation, smooth muscle and endothelial cell proliferation, nerve activity, and tissue perfusion. ${ }^{18}$ Research among men with or without erectile dysfunction (ED) and LUTS has shown that tadalafil has a beneficial effect on LUTS independent of the drug's benefit on ED. ${ }^{19-23}$ Indeed, a head-to-head comparison of tadalafil with the alpha-blocker tamsulosin showed similar improvements of LUTS due to BPH with each agent. ${ }^{23}$

\section{Conclusions}

Male LUTS are extremely common. They are often associated with histological $\mathrm{BPH}$, prostate enlargement, and measurable obstruction. For many reasons, measures of these conditions do not correlate highly at baseline. However, there are strong correlations between some baseline measures and changes or outcomes over time, which are clinically useful and allow for differentiated treatment assignments. The AUA, EAU, NICE and International Consultation on Urologic Disease (ICUD) guidelines all provide evidence-based treatment algorithms. The newest drug class (PDE-5 inhibitors, e.g., tadalafil) is not yet incorporated into any guidelines (although they are discussed as emerging therapies in the 2012 EAU guidelines, they will likely be included during ICUD sessions during the Société Internationale d'Urologie congress in autumn 2012).

Competing interests: Dr. Roehrborn is an ongoing paid consultant with Neo Tract, NxThera, Afferent, Astellas, GlaxoSmithKline, and Eli Lilly.

\section{References}

1. Roehrborn CG, McConnell JD. Etiology, pathophysiology, epidemiology and natural history of benign prostatic hyperplasia. In: Campbell's Urology. 8th ed. Philadelphia, Pa: W.B. Saunders Co; 2001:1297-1336.

2. Oelke M, Bachmann A, Descazeaud A, et al. Guidelines on the Management of Male Lower Urinary Tract Symptoms (LUTS), incl. Benign Prostatic Obstruction (BPO). European Association of Urology, 2012. http://www.uroweb.org/gls/pdf/12_Male_LUTS_LR.pdf (Accessed August 23, 2012).

3. McVary KT, Roehrborn CG, Avins AL, et al. American Urological Association Guideline: Management of Benign Prostatic Hyperplasia. American Urological Association, 2010. http://www.auanet.org/ content/guidelines-and-quality-care/clinical-guidelines/main-reports/bph-management/chap_1_ GuidelineManagementof(BPH).pdf (Accessed August 23, 2012).

4. National Institute for Health and Clinical Excellence. Lower urinary tract symptoms: The management of lower urinary tract symptoms in men. National Institute for Health and Clinical Excellence, 2010. http:// publications.nice.org.uk/lower-urinary-tract-symptoms-cg97 (Accessed August 23, 2012).

5. Abrams $P$, Chapple $C$, Khoury $S$, et al. Evaluation and treatment of lower urinary tract symptoms in older men. J Urol 2009;181:1779-87. http://dx.doi.org/10.1016/i.juro.2008.11.127 
Roehrborn

6. Abrams P, Kaplan S, De Koning Gans HJ, et al. Safety and tolerability of tolterodine for the treatment of overactive bladder in men with bladder outlet obstruction. J Urol 2006;175 (3 Pt 1):999-1004. http:// dx.doi.org/10.1016/50022-5347(05)00483-0

7. Abbott Laboratories Limited. Hytrin $®$ Product Monograph. Date of revision, December 13, 2010.

8. Pfizer Canada Inc. Cardura $\circledast$ Product Monograph. Date of revision, November 23, 2009.

9. Boehringer Ingelheim (Canada) Ltd. Flomax® Product Monograph. Date of Revision, September 21, 2011.

10. sanofi-aventis Canada Inc. Xatral $\circledast$ Product Monograph. Date of revision, July 30, 2010.

11. Watson Laboratories, Inc. Rapaflo ${ }^{\mathrm{TM}}$ Product Monograph. Date of preparation, January 10, 2011.

12. Kaplan SA, McConnell JD, Roehrborn CG, et al. Combination therapy with doxazosin and finasteride for benign prostatic hyperplasia in patients with lower urinary tract symptoms and a baseline total prostate volume of $25 \mathrm{ml}$ or greater. J Urol 2006;175:217-20. http://dx.doi.org/10.1016/S0022$5347(05) 00041-8$

13. Montorsi F, Roehrborn C, Garcia-Penit J, et al. The effects of dutasteride or tamsulosin alone and in combination on storage and voiding symptoms in men with lower urinary tract symptoms (LUTS) and benign prostatic hyperplasia (BPH): 4-year data from the Combination of Avodart and Tamsulosin (CombAT) study. BJU Int 2011;107:1426-31. http://dx.doi.org/10.1111/j.1464-410X.2011.10129.x

14. Lee JY, Kim HW, Lee SJ, et al. Comparison of doxazosin with or without tolterodine in men with symptomatic bladder outlet obstruction and an overactive bladder. BJU Int 2004;94:817-20. http://dx.doi. org/10.1111/i.1464-410X.2004.05039.x

15. Kaplan SA, Roehrborn CG, Rovner ES, et al. Tolterodine and tamsulosin for treatment of men with lower urinary tract symptoms and overactive bladder: a randomized controlled trial. JAMA 2006;296:2319-28. http://dx.doi.org/10.1001/jama.296.19.2319

16. Drake $M$, Speakman $M$, van Kerrebroeck $P$, et al. Evaluating the Efficacy and Safety of Fixed-Dose Combinations of Tamsulosin OCASTM and Solifenacin in male LUTS with Storage and Voiding Symptoms: An Overview of the NEPTUNE Trial [SIU abstract \#MP-05.01]. Urology 2011;78(Suppl.3A):S58. http:// dx.doi.org/10.1016/j.urology.2011.07.099

17. Wyndaele J, Cicalese AR, IJzerman W, et al. Combination Therapy with Tamsulosin OCASTM and Solifenacin is more Effective than Solifenacin Monotherapy as a Treatment for Male LUTS Associated with BPH: Results from the SATURN Trial [SIU abstract \#MP-05.02]. Urology 2011;78(Suppl.3A):S58. http://dx.doi. org/10.1016/i.urology.2011.07.100
18. Andersson KE, de Groat WC, MCVary KT, et al. Tadalafil for the treatment of lower urinary tract symptoms secondary to benign prostatic hyperplasia: pathophysiology and mechanism(s) of action. Neurourol Urodyn 2011;30:292-301. http://dx.doi.org/10.1002/nau.20999

19. Roehrborn CG, McVary KT, Elion-Mboussa A, et al. Tadalafil administered once daly for lower urinary tract symptoms secondary to benign prostatic hyperplasia: a dose finding study. J Urol 2008;180:1228-34. http://dx.doi.org/10.1016/i.juro.2008.06.079

20. Donatucci $C F$, Brock GB, Goldfischer ER, et al. Tadalafil administered once daily for lower urinary tract symptoms secondary to benign prostatic hyperplasia: a 1-year, open-label extension study. BJU Int 2011:107:1110-6. http://dx.doi.org/10.1111/i.1464-410X.2010.09687.x

21. Egerdie RB, Auerbach S, Roehrborn CG, et al. Tadalafil 2.5 or $5 \mathrm{mg}$ administered once daily for 12 weeks in men with both erectile dysfunction and signs and symptoms of benign prostatic hyperplasia: results of a randomized, placebo-controlled, double-blind study. J Sex Med 2012;9:271-81. http://dx.doi. org/10.1111/i.1743-6109.2011.02504.x

22. Broderick GA, Brock GB, Roehrborn CG, et al. Effects of tadalafil on lower urinary tract symptoms secondary to benign prostatic hyperplasia in men with or without erectile dysfunction. Urology 2010;75:1452-8. http://dx.doi.org/10.1016/j.urology.2009.09.093

23. Oelke $M$, Giuliano F, Mirone V, et al. Monotherapy with tadalafil or tamsulosin similarly improved lower urinary tract symptoms suggestive of benign prostatic hyperplasia in an international, randomised, parallel, placebo-controlled clinical trial. Eur Urol 2012;61:917-25. http://dx.doi.org/10.1016/i. eururo.2012.01.013

Correspondence: Dr. Claus Roehrborn, The University of Texas Southwestern Medical Center at Dallas, Department of Urology, 5323 Harry Hines Blvd., J8-130, Dallas, TX 75390-9110; fax: 214-648-3453; Claus.Roehrborn@UTSouthwestern.edu 